\title{
A Study on Ontology Application Scenarios in e- Learning Domain
}

\author{
Kalla Madhusudhana \\ Professor, Department of CSE \\ CVR College of Engineering, Hyderabad, India
}

\begin{abstract}
The e-Learning community is aiming to provide much more effective computer aided learning management systems. The exploration of huge learning material and evolution of elearning technology caused realizing of various approaches and techniques in learning content management and delivery process. However, searching appropriate learning resources for a learner from a large number of heterogeneous knowledge sources is a tedious task. This paper discusses how ontology can be used to the e-learning system to help learner in selecting or retrieving relevant learning material and investigates different ontology application scenarios in the elearning environments. Finally we proposed the different strategies to be considered while developing ontologies in management, presentation and retrieval of the material in elearning domain.
\end{abstract}

\section{Keywords}

e-learning, ontology, application scenarios, Metadata, Semantic Web, Presentation, Personalization, Adaptation.

\section{INTRODUCTION}

The recent advances in e-learning technologies provide learners with availability of huge learning material in variety of forms. The learning management system is responsible to organize and deliver the learning content as per the preferences and needs of learner. The educational systems are gradually incorporating semantic web technologies aiming to provide an intelligent learning environment [1]. The semantic web technologies provide us with tools for describing and annotating resources on the web in standardized ways [2]. That is enabling us to tailor the content delivery as per the personalized and contextual needs of individual users.

In order to structure the concepts of particular subject domain there is a need to define relationships among concepts with similar subjective characteristics. The ontologies share many structural similarities, and they can represent the semantic knowledge in the form of concepts and relations with appropriate axioms. The ontologies can be used to index data indicating their meaning, thereby making their semantics explicit and machine- accessible.

Monachesi, P., et al. [3], addressed how ontologies play a key role in the semantic web vision and by considering LT4eL(www.lt4el.eu) project as test case, and discussed about how they can contribute to e-Learning to enhance the learning process. In particular, he considered the semantic search facility which has been implemented in the context of this project. The applicability and approach for building ontologies in the pedagogical resources management for elearning addressed by [4]

The digital educational resources availability and extensive integration of information technology in e-learning domain, have initiated changes in educational paradigm. The computer aided instruction (CAI) influenced the first generation of webbased educational systems, recently, the design of web-based learning systems started to move in a direction of artificial intelligence in education. Nowadays, web-based educational systems are facing challenges that include: Semantic based presentation, retrieval, structuring of learning resources and context aware adaptation, recommendation, and personalized delivery as per the learner needs. It is also required to consider the cognitive prerequisites of a learner, as an important step towards delivering contents of a domain.

The Semantic Web can be used as a technology for realizing sophisticated eLearning scenarios. In the following, we will first discuss metadata in educational domain. In the subsequent section the application ontology in e-learning domain for various purposes is presented finally the Semantic Web Stack structure in the context of educational domain is presented.

\section{METADATA FOR E-LEARNING}

In the E-Learning community it is important to observe that the resources considered as learning objects should be described by external descriptions called metadata. These metadata are descriptions about the learning objects. Metadata "says something" about the learning object, in a general sense and Metadata is physically external to the educational resource; they can be in a separate file or be obtained from a different service.

The current existing metadata standards are not providing fully educative support information and also they are not completely suitable enough to integrate Semantic Web technologies [5]. The current e-learning standards are conceived especially for learning management purposes, and not for integration with various Semantic Web applications. In the context of educational domain the semantic description of learning resources consists of different types of interrelations among them.

The new generation of Web-based Educational Systems aims at providing several improvements on the Quality of Services (QoS) through the use of Semantic Web technology [1]. The learning resources associated with metadata are meant to be reusable in different contexts and they can easily be searchable and manageable. Metadata use a technical format for expressing structural information of educational resources.

One of the main approaches for creating metadata for learning resources in adaptive e-learning systems has been through the use of semantic web ontologies [6]. In order to make the computers to understand content semantics, it is necessary to represent the learning content metadata information in the form of ontology. Ontologies have the potential to play an important role in representing knowledge about content to support learners in accessing content in a knowledge-guided way. It is also useful for structuring and grouping the learning material as per the course and the curriculum requirements. 
Because of the variation and heterogeneity, different metadata cannot work with each other. Creating a common understanding between terms in various metadata, vocabularies can be helpful. The most important issues for searching learning materials which are considered by the learners are:

- Content: What the learning materials about.

- Context: In which form learning material is presented.

- Structure: How a set of learning materials merge and create a learning course.

Therefore, by using ontology in each of the above mentioned issues, improve web based education significantly.

\section{ONTOLOGY IN WEB-BASED EDUCATIONAL SYSTEMS}

In the computing context, an ontology is a framework for representing concepts and the relationships that exist between those concepts [7]. Ontology technology is considered to be a highly suitable means of supporting educational-technology systems $[8,9]$.

In an intelligent e-learning environment the instructors no longer control the delivery of material as per the learner needs. The content is useless unless it can be searched and indexed easily. Providing semantic rich environments is one essential requirement in the current education system. By providing domain knowledge representation, can support interoperability of learn-ing material. That requires the construction of educational ontology that is different from ontology constructed for other domains.

As shown in Figure 1, in e-learning environment ontologies can be used at learner side (User Interface) and domain side (Structuring Educational Resources). User Interface Environment has to support the different roles such as Personalization, Adaptation and Recommendation. The Educational Resources represent the resources invoked by users in the interaction with User Interface, in this the technique of Structuring, Retrieval and Presentation of resources plays important role.

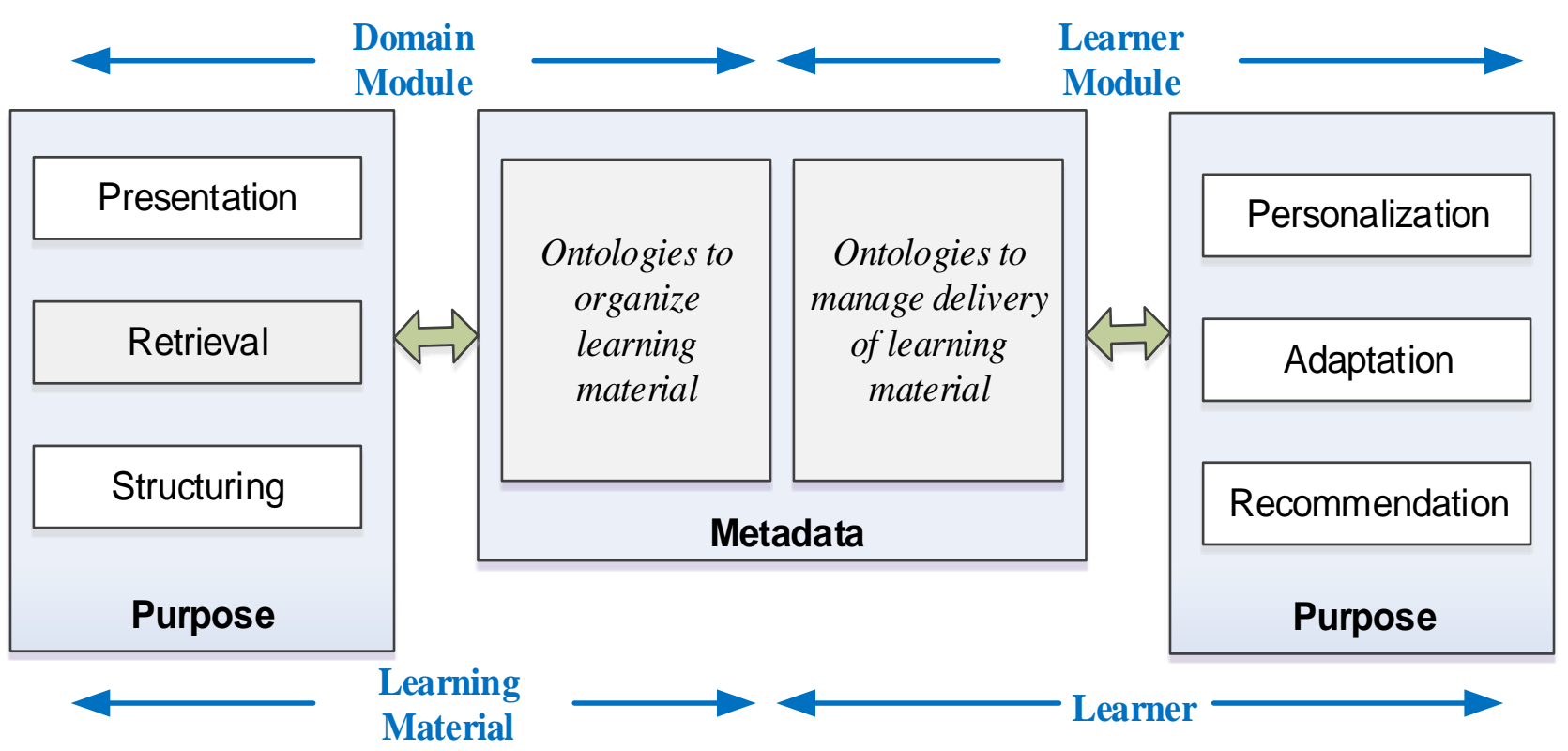

Fig 1: Ontology Applications in E-learning Domain

\subsection{Presentation}

While in traditional learning it is the instructor who determines the agenda, within eLearning this task is left to the student [3]. The course content presentation and navigation based on semantic relations, facilitates the learner to improve the understandability of e-learner. Learner can refer to a wide range of different concepts that are concerned to learning topic. This approach facilitates the acquisition of new knowledge by the students through studying the related concepts.

\subsection{Retrieval}

The learner demands, backgrounds, and users' preference are to be considered for effectively searching the learner expected materials. This semantic based structuring of learning resources can be used by a semantic search mechanism to return results that are more relevant to the user query compared with keyword based approach. The ontology based description learning material provides search mechanism to deliver relevant results based on domain specific knowledge and improves both the precision and recall.

\subsection{Structuring}

For structuring of learning content there are many metadata standards such as SCORM Metadata [10], IMS Metadata [11], Dublin Core Metadata [12], IEEE Learning Object Metadata [13], etc., developed by different organizations and have proven their benefits to e-learners. For the recent development in semantic-web technology and the pedagogical requirements of e-learner there is a need to enrich the existing metadata standards so as to make them suitable for current requirements. It is believed that the existing metadata should be represented in ontological format so as to support Educational Semantic-web Vision.

\subsection{Personalization}

In e-learning domain, one of the challenges in the coming years is to personalize learning material in order to provide each learner with an individualized learning plan. Personalization is the process of delivering learning material as per the requirements and preferences of learner. Personalization can be performed based on various descriptors that are mainly concerned to learner-personal details, learner- 
preferences and learning environment. Ontology based learner-model allow to understand learner requirements and provides mechanism to deliver personalized learning material to learner.

\subsection{Adaptation}

The adaptive modeling the context, cognitive skills or learning style is needed to better understand the user's activities and to adapt the content to his requirements. This leads to the design of adaptive systems that deliver more suitable learning content to satisfy learner requirement. The ontologically represented subject, instruction, and user knowledge can be used to adapt the content as per the learner status.

\subsection{Recommendation}

A knowledge-based recommender will typically need to know different features that are associated with learning content. Hyon Hee Kim [14], presents a method for personalized recommendation services using a tagging ontology for a social e-learning system.

\section{THE SEMANTIC WEB AND EDUCATIONAL SYSTEM}

Now in the area of Internet based educational system the big question is what is the next step in the evolution of elearning? And what do we need to do in order to realize the
Vision of Educational Semantic Web [15]. Educational systems are gradually incorporating semantic web technologies aiming to provide a more adaptable, personalized and intelligent learning environment.

The web-based educational systems is playing an important role in the improvement of quality of learning, that needs quality of educational content, pedagogical approaches in elearning environments and personalized resource delivery framework. The web-based systems are in need of domain ontologies, methodology to solve contextualization issues, standardized semantic based metadata, dynamic sequencing of learning contents, new models of learning, and so on.

The research directions in the field of Semantic Web and Education field have to consider the challenges related to knowledge representation, architectures, ontologies, and pedagogical and cognitively sound learning applications that can yield the new generation of intelligent e-learning systems. With more semantic-aware computing technologies, elearning is expected to be more intelligent in the new era of Educational Semantic Web. To facilitate the transforming process towards the Educational Semantic Web vision, the following is the well-known Semantic Web cake stack, where the existing information architecture in e-learning application could be described as a layered architecture as shown in above Figure 2.

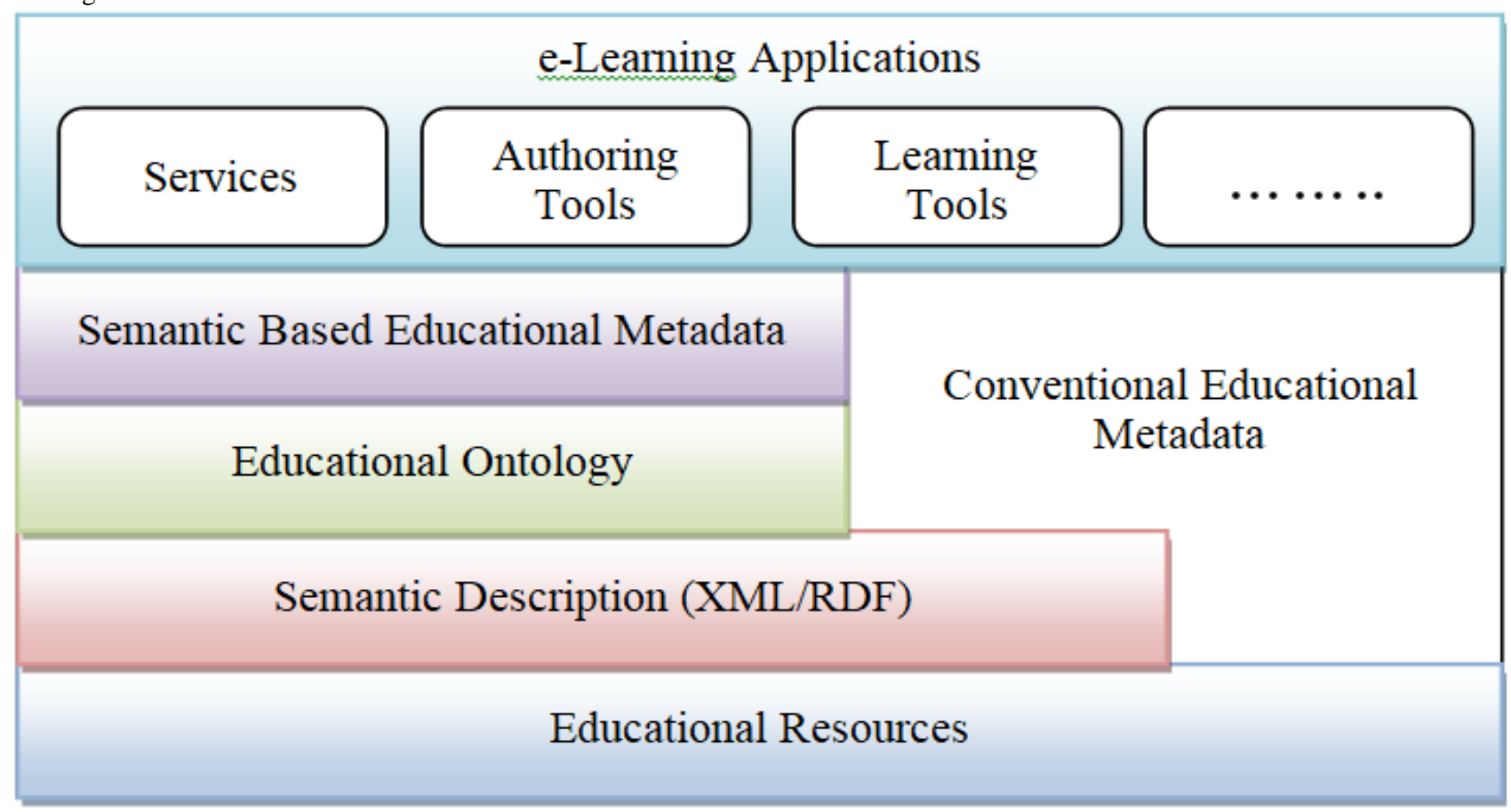

Fig 2: Educational Semantic Web Stack

\section{CONCLUSION}

By means of Semantic Web technologies there will be considerable success in intelligent Web-based education that takes on new dimensions. The recent fast development of Semantic Web technologies such as XML/RDF and ontologies has enabled a possibility for semantic-based elearning services in the future. In this paper we discussed various approaches of using ontology in e-learning environment. It is primarily based on learner side and learning materials side. However, in this paper, we are only concerned with discussing various approaches in learning content management and delivery process. The ontology applicability in security and trust issues of e-learning domain have to be further investigated. Finally, it is important to emphasize that an application of Semantic Web technology can provides an ideal framework for the standardization of the e-learning.

\section{REFERENCES}

[1] Bittencourt, Ig Ibert, Seiji Isotani, Evandro Costa, and Riichiro Mizoguchi. "Research directions on Semantic Web and education." Scientia Interdisciplinary Studies in Computer Science 19(1): 60-67, January/June 2008.

[2] Guo, WenYing. "An Ontology-Based e-Learning Scenario." In Methods and Applications for Advancing 
Distance Education Technologies: International Issues and Solutions, pp. 63-71. IGI Global, 2009.

[3] Monachesi, P., Simov, K., Mossel, E., Osenova, P.: What ontologies can do for eLearning. In: Proceedings of International Conference on Interactive Mobile and Computer Aided Learning, IMCL 2008 (2008)

[4] Abel, Marie-Hélène, Ahcène Benayache, Dominique Lenne, Claude Moulin, Catherine Barry, and Brigitte Chaput. "Ontology-based organizational memory for elearning." Educational technology \& society 7, no. 4 (2004): 98-111.

[5] Sudhana, Kalla Madhu, V. Cyril Raj, and R. M. Suresh. "An ontological approach for enriching metadata of learning objects to support effective e-learning." International Journal of Computer Science and Network Security 12 , no. 10 (2012): 68-73.

[6] Bateman, Scott, Christopher Brooks, and Gord McCalla. "Collaborative tagging approaches for ontological metadata in adaptive e-learning systems." In Proceedings of the fourth international workshop on applications of semantic web technologies for e-learning (SW-EL 2006), pp. 3-12. 2006.

[7] Uschold, Mike, and Michael Gruninger. "Ontologies: Principles, methods and applications." The knowledge engineering review 11, no. 2 (1996): 93-136.

[8] Dicheva, Darina. "Ontologies and semantic web for elearning." Handbook on information technologies for education and training (2008): 47-65.
[9] [Aroyo et al. , 2002]Aroyo, Lora, Darina Dicheva, and Alexandra Cristea. "Ontological support for web courseware authoring." In Intelligent tutoring systems, pp. 270-280. Springer Berlin/Heidelberg, 2002.

[10] SCORM, http://scorm.com/scorm-explained/technicalscorm/content-packaging/metadata-structure/

[11] IMS Global Learning Consortium. http://www.imsproject.org/metadata/imsmdv1p2p1/imsm d_bestv1p2p1.html

[12] DCMI (2008). Dublin Core Metadata Element Set, Version 1.1. DCMI Recommendation. http://dublincore.org/documents/dces/.

[13] IEEE LTSC. (2002). Draft Standard for Learning Object Metadata (IEEE 1484.12.1-2002) http://ltsc.ieee.org/wg12/files/LOM_1484_12_1_v1_Fina 1_Draft.pdf.

[14] Hyon Hee Kim. "A personalized recommendation method using a tagging ontology for a social e-learning system". In Proceedings of the Third international conference on Intelligent information and database systems - Volume Part I, ACIIDS'11, pages 357-366, 2011.

[15] Aroyo, Lora, and Darina Dicheva, "The New Challenges for E-Learning: The Educational Semantic Web", Educational Technology Soc., no. 4, pp. 59-69, 2004. 